\title{
Representing Wind Turbine Electrical Generating Systems in Fundamental Frequency Simulations
}

\author{
J. G. Slootweg, Member, IEEE, H. Polinder, Member, IEEE, and W. L. Kling, Member, IEEE
}

\begin{abstract}
Increasing numbers of wind turbines are being erected. In the near future, they may start to influence the dynamics of electrical power systems by interacting with conventional generation equipment and with loads. The impact of wind turbines on the dynamics of electrical power systems therefore becomes an important subject, studied by means of power system dynamics simulations. Various types of power system dynamics simulations exist and the approach depends on the aspect of power system dynamic behavior being investigated.

In this paper, the focus is on fundamental frequency simulations, also known as electromechanical transient simulations. In this type of simulation, the network is represented as an impedance matrix and only the fundamental frequency component of voltages and currents is taken into account in order to reduce the computation time. This simulation approach is mainly used for voltage and angle stability investigations. Models of wind turbine generating systems that match the fundamental frequency simulation approach are presented and their responses are compared to measurements.
\end{abstract}

Index Terms-Grid interaction, modeling, power system dynamics, simulation, wind power.

\section{NOMENCLATURE}

$\mathrm{A}_{\mathrm{wt}} \quad$ Rotor area of wind turbine $\left(\mathrm{m}^{2}\right)$.

c Numerical constant.

f Frequency $(\mathrm{Hz})$.

i Current (p.u.).

$\mathrm{K}_{\mathrm{s}} \quad$ Shaft stiffness (p.u./el. rad.).

L Inductance (p.u.).

$\mathrm{P} \quad$ Active power (p.u.) or (W) [indicated in text].

Q Reactive power (p.u.).

R Resistance (p.u.).

s Slip or complex frequency $(\mathrm{Hz})$ [indicated in text].

T Torque (p.u.).

$\mathrm{v}_{\mathrm{W}} \quad$ Wind speed $(\mathrm{m} / \mathrm{s})$.

$\mathrm{v}_{\mathrm{t}} \quad$ Speed of rotor blade tips $(\mathrm{m} / \mathrm{s})$.

v Voltage (p.u.).

$\gamma \quad$ Displacement between shaft ends (el. rad.).

$\theta \quad$ Pitch angle (deg.).

$\lambda \quad$ Tip speed ratio.

$\lambda_{\mathrm{i}} \quad$ Intermediate result in calculation of $c_{\mathrm{p}}$.

$\rho \quad$ Air density $\left(\mathrm{kg} / \mathrm{m}^{3}\right)$.

$\tau \quad$ Low pass filter time constant (s).

$\psi \quad$ Flux linkage (p.u.).

$\omega \quad$ Frequency (p.u.).

Manuscript received October 18, 2002. This work was supported in part by the Dutch Organization for Scientific Research.

The authors are with the Faculty of Electrical Engineering, Mathematics and Computer Science, Delft University of Technology, Delft 2600 GA, The Netherlands (e-mail: H.Polinder@ewi.tudelft.nl).

Digital Object Identifier 10.1109/TEC.2003.816593

\author{
Indexes \\ Converter. \\ Direct. \\ Generator electrical. \\ Field winding of synchronous generator. \\ Generator mechanical. \\ Mutual. \\ Performance. \\ Permanent magnet. \\ Quadrature. \\ Rotor. \\ Stator. \\ Wind turbine. \\ Leakage.
}

\section{INTRODUCTION}

A S A RESULT of increasing environmental concern, the impact of conventional electricity generation on the environment is being minimized and efforts are being made to generate electricity from renewable sources. One way of generating electricity from renewable sources is to use wind turbines that convert the energy contained in flowing air into electricity.

Up to this moment, the amount of wind power generation integrated into large-scale electrical power systems only covers a small part of the total power system load. However, a tendency to increase the amount of electricity generated from wind can be observed. Therefore, the penetration of wind turbines in electrical power systems will increase and they may begin to influence overall power system behavior.

To study the dynamics of large-scale power systems, a special simulation approach is used. This approach will further be referred to as fundamental frequency simulation and will be discussed in Section II. To allow the investigation of the impact of high wind power penetrations on electrical power systems, models of wind turbine generating systems must be incorporated in software packages in which the fundamental frequency simulation approach is applied. These models must, of course, match the assumptions and simplifications generally made in fundamental frequency simulations.

Numerous models to represent wind turbine generating systems can be found in the literature. However, most of these cannot easily be used for fundamental frequency simulations either because

- they focus on one subsystem of the wind turbine generating system, such as the generator [1], [2], the drive train and mechanical structure [3], [4], or the controllers [5], 
[6], while neglecting the other subsystems, whereas for investigation of the impacts of wind power on power system dynamics complete models are necessary;

- they are, although advanced, not very well documented and specified [7];

- they contain time constants which are too short to be taken into account in fundamental frequency simulations [8], [9];

- they model generating systems that are not applied in wind turbines anymore [10].

The contribution of this paper is threefold, because it presents models of widely used generating systems that

- match the assumptions made in the fundamental frequency simulation approach;

- contain models of all subsystems that effect the interaction between the wind turbine generator and the grid, which is the main focus in fundamental frequency simulations;

- are fully documented, including all subsystems.

The model responses to a measured wind-speed sequence are simulated and compared to measurements to investigate the consequences of the applied simplifications and assumptions and the accuracy of the models.

\section{Fundamental FREQUENCY Simulation}

Power system dynamics simulation software is used to investigate the dynamic behavior and small signal stability of power systems. A large power system can easily have hundreds or even thousands of states that are associated with branches, with generators and their controllers and, when dynamic load models are used, also with loads. When the aspect of power system behavior that is of interest is characterized by rather low frequencies/long time constants, long simulation runs are required. A simulation run of sufficient length would, however, take a substantial amount of computation time when all fast, high-frequency phenomena would be included in the applied models. This makes it difficult and time consuming to study various scenarios and setups when the investigated power system is large.

To solve this problem, only the fundamental frequency component of voltages and currents is taken into account when studying low-frequency phenomena. This approach enables the representation of the network by a constant impedance or admittance matrix, like in load-flow calculations. The associated equations can thus be solved using load-flow solution methods. Further, the approach reduces the number of differential equations, because no differential equations are associated with the network and fewer with generating equipment and because it enables the use of a larger simulation time step [11]. Examples of a fundamental frequency simulation packages are PSS/E and Eurostag. This type of software can be used when the phenomena of interest have a frequency of about 0.1 to $10 \mathrm{~Hz}$. The typical problems studied using these programs are voltage and angle stability.

When the frequencies of interest are higher, instantaneous value simulation software, such as ATP, EMTP, or the MATLAB@ Power System Blockset must be used. These packages contain more detailed and higher order equipment models than fundamental frequency simulation software. However, their time step is much smaller and simulation of a large-scale power system in these programs is therefore hardly practically feasible.

Some advanced software packages, such as Power Factory from DIgSILENT, NETOMAC@, and Simpow@, offer both fundamental frequency and instantaneous value modes of simulation. They may even be able to automatically switch between the fundamental frequency and instantaneous value domains, each with their own models, depending on the simulated event and/or the user's preferences. Fundamental frequency and instantaneous value simulations are also referred to as electromechanical and electromagnetic transient simulations, respectively.

\section{Wind Turbine Generating SySTEM MODELing}

\section{A. Wind Turbine Generating Systems}

Three different wind turbine generating systems are currently widely applied. The first is the directly grid coupled squirrel cage induction generator, used in constant speed wind turbines. The wind turbine rotor is coupled to the generator through a gearbox. In most turbines using this system, the power extracted from the wind is limited using the stall effect. This means that the rotor is designed in such a way that its aerodynamic efficiency decreases in high wind speeds, thus preventing extraction of too much mechanical power from the wind. When the stall effect is used, no active control systems are necessary. Pitch controlled constant speed wind turbines have, however, also been built.

The second system is the doubly fed (wound rotor) induction generator, which allows variable speed operation. The rotor winding is fed using a back-to-back voltage source converter. Like in the first system, the wind turbine rotor is coupled to the generator through a gearbox. In high wind speeds, the power extracted from the wind is limited by pitching the rotor blades.

The third system is a direct drive synchronous generator, also allowing variable speed operation. The synchronous generator can have a wound rotor or be excited using permanent magnets. It is grid coupled through a back-to-back voltage source converter or a diode rectifier and voltage source converter. The synchronous generator is a low speed multipole generator; therefore, no gearbox is needed. Like in the second system, the power extracted from the wind is limited by pitching the rotor blades in high wind speeds. The three wind turbine generating systems are depicted in Fig. 1.

\section{B. Modeling Assumptions}

In order to keep the data requirements and the computation time within limits, a quasi static approach is used to describe the rotor. This means that an algebraic relation is assumed between the wind speed at hub height and the mechanical power extracted from the wind. More advanced methods, such as the blade element impulse method, require detailed knowledge of aerodynamics and of the wind turbine blade characteristics [12], [13]. These data will often not be available and the impact on the grid interaction is assumed to be rather limited.

In this paper, models for representing wind turbine generating systems in fundamental frequency simulations are presented. 


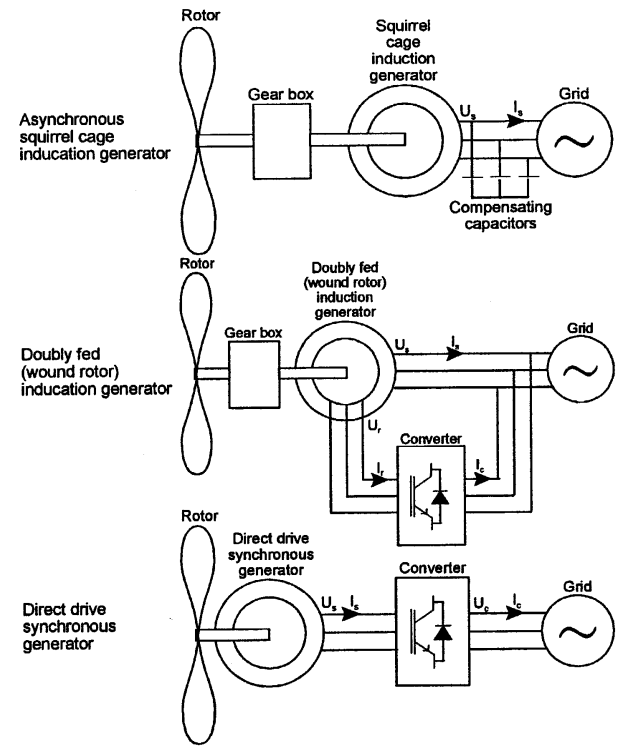

Fig. 1. Frequently occurring wind turbine generating systems.

The models must comply with the requirements that result from the principles on which fundamental frequency simulation software is based, as described in Section II. This results in a number of assumptions. The following assumptions apply to the model of each generating system.

- Magnetic saturation is neglected.

- Flux distribution is sinusoidal.

- Any losses apart from copper losses are neglected.

- Stator voltages and currents are sinusoidal at the fundamental frequency.

Furthermore, the following assumptions apply to some of the investigated generating systems.

- In both variable speed systems, all rotating mass is represented by one element, the so-called "lumped-mass" representation.

- In both variable speed systems, the voltage source converters with current control loops are modeled as current sources.

- In the system based on the doubly fed induction generator, rotor voltages and currents are sinusoidal at the slip frequency.

- In the direct drive wind turbine, the synchronous generator has no damper windings.

- When a diode rectifier is used in the direct drive wind turbine, commutation is neglected.

The first of these assumptions is made because the mechanical and electrical properties of variable speed wind turbines are decoupled by the power electronic converters. Therefore, the shaft properties are hardly reflected in the grid interaction, which is the main point of interest in power system studies [14], [15].

The next two assumptions are made in order to allow modeling of power electronics in power system dynamics simulation software and are routinely applied in power system dynamics simulations [11], [16], [17]. A full converter model would require a substantial reduction of the simulation time step and, hence, does not match the goal of this work.

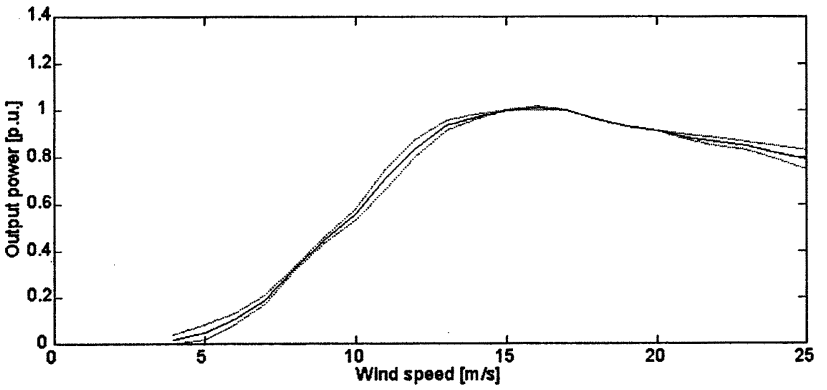

Fig. 2. Comparison of numerical approximation of the power curve of a stall controlled wind turbine (solid) with the power curves of two existing stall controlled wind turbines (dotted).

The fourth assumption is made because taking into account the damper windings in the synchronous generator is not necessary. When a back-to-back voltage source converter is used, generator speed is controlled by the power electronic converter, which will prevent oscillations. When a diode rectifier is used, damper windings are essential for commutation. However, commutation is neglected according to the last assumption and, therefore, the damper windings can be neglected as well.

\section{Generating System With Squirrel Cage Induction Generator}

1) Rotor Model: The following well-known algebraic equation gives the relation between wind speed and mechanical power extracted from the wind [12], [13]:

$$
P_{w t}=\frac{\rho}{2} A_{w t} c_{p}(\lambda, \theta) v_{w}^{3}
$$

with $P_{\mathrm{wt}}$ the power extracted from the wind $(\mathrm{W}), \rho$ the air density $\left(\mathrm{kg} / \mathrm{m}^{3}\right), c_{\mathrm{p}}$ the performance coefficient or power coefficient, $\lambda$ the tip speed ratio $\mathrm{v}_{\mathrm{t}} / \mathrm{v}_{\mathrm{w}}$, the ratio between blade tip speed $\mathrm{v}_{\mathrm{t}}(\mathrm{m} / \mathrm{s})$ and wind speed at hub height upstream the rotor $\mathrm{v}_{\mathrm{w}}(\mathrm{m} / \mathrm{s})$, the pitch angle $\theta\left(\right.$ deg.), and $A_{\mathrm{wt}}$ the area covered by the wind turbine rotor $\left(\mathrm{m}^{2}\right)$. In case of a stall controlled wind turbine, $\theta$ is left out and $c_{p}$ is a function of $\lambda$ only.

When manufacturer documentation is consulted, it can be concluded that the power curves of individual wind turbines show a high degree of similarity. It is therefore not considered necessary to use different approximations for the $c_{p}(\lambda)$ curve for different constant speed wind turbines in power system dynamics simulations. Instead, a general approximation can be used. In this paper, the following is used:

$$
c_{p}(\lambda, \theta)=c_{1}\left(\frac{c 2}{\lambda_{i}}-c_{3} \theta-c_{4} \theta^{c_{5}}-c_{6}\right) e^{-\frac{c_{7}}{\lambda_{i}}}
$$

with

$$
\lambda_{i}=\frac{1}{\frac{1}{\lambda+c_{8} \theta}-\frac{c_{9}}{\theta^{3}+1}} .
$$

The structure of this equation is obtained from [12] but the value of the constants $c_{1}$ to $c_{9}$ has been slightly changed in order to get better correspondence with manufacturer data. To minimize the error between the curve found in the manufacturer documentation and the curve obtained using (2) and (3), multidimensional optimization has been applied. Both the original parameters and the parameters used here are given in Table 1. In Fig. 2, the power curves of two commercial wind turbines 
TABLE I

APPROXIMATION OF POWER CURVES

\begin{tabular}{l|l|l|l|l|l|l|l|l|l}
\hline & $\mathrm{c}_{1}$ & $\mathrm{c}_{2}$ & $\mathrm{c}_{3}$ & $\mathrm{c}_{4}$ & $\mathrm{c}_{5}$ & $\mathrm{c}_{6}$ & $\mathrm{c}_{7}$ & $\mathrm{c}_{8}$ & $\mathrm{c}_{9}$ \\
\hline Ref. [12] & 0.5 & 116 & 0.4 & 0 & - & 5 & 21 & 0.08 & 0.035 \\
\hline Const. Spd. & 0.44 & 125 & 0 & 0 & 0 & 6.94 & 16.5 & 0 & -0.002 \\
\hline Var. speed & 0.73 & 151 & 0.58 & .002 & 2.14 & 13.2 & 18.4 & -0.02 & -0.003 \\
\hline
\end{tabular}

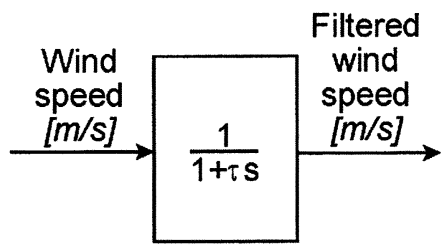

Fig. 3. Low-pass filter.

are depicted, together with the generic numerical approximation from Table 1.

High-frequency wind-speed variations are very local and, therefore, even out over the rotor surface. To approximate this effect, a low pass filter is included in the rotor model. The low pass filter is depicted in Fig. 3. The value of the time constant $\tau$ depends on the rotor diameter and also on the turbulence intensity of the wind and the average wind speed. For the wind turbines investigated here, $\tau$ has been set to $4 \mathrm{~s}$.

Further, a periodic torque pulsation is added to the torque calculated from the wind speed to represent the tower shadow, which can be clearly distinguished in measurements [7]. The amplitude of the torque pulsation equals 0.1 p.u., its frequency is equal to the number of blades times the rotor frequency, which equals $1.5 \mathrm{~Hz}$ in the case of the simulated turbine.

2) Shaft Model: It has been repeatedly argued in the literature that incorporating a shaft representation in a model of a constant speed generating system is very important for a correct representation of the behavior during and after voltage drops and short circuits [7]. A two mass representation has been chosen here, which is described by the following:

$$
\begin{aligned}
\frac{d \omega_{w t}}{d t} & =\frac{T_{w t}-K_{s} \gamma}{2 H_{w t}} \\
\frac{d \omega_{g}}{d t} & =\frac{K_{s} \gamma-T_{e}}{2 H_{g}} \\
\frac{d \gamma}{d t} & =2 \pi f\left(\omega_{w t}-\omega_{g}\right)
\end{aligned}
$$

in which $\mathrm{f}$ is the nominal grid frequency, $\mathrm{T}$ is torque, $\gamma$ is the angular displacement between the two ends of the shaft, $\omega$ is frequency, $\mathrm{H}$ is the inertia constant, and $\mathrm{K}_{\mathrm{S}}$ is the shaft stiffness. The indexes wt, $\mathrm{g}$, and e stand for wind turbine, generator mechanical, and generator electrical, respectively. All values are in per unit, apart from $\mathrm{K}_{\mathrm{s}}, \gamma$ and $\mathrm{f}$, which are in per unit/el. rad., deg., and Hertz, respectively.

The resonance frequency of the shaft torsional mode has been experimentally determined as $1.7 \mathrm{~Hz}$ [7]. When resonance frequency and the inertia constants of the generator and the turbine rotor are known, $\mathrm{K}_{\mathrm{S}}$ can be calculated.

3) Generator Model: The generator in the constant speed generating system is a squirrel cage induction generator, whose stator transients are neglected as is normal in fundamental frequency simulations [11]. The following voltage-current rela- tionships apply in the dq reference frame, using the generator convention:

$$
\begin{aligned}
& v_{d s}=-R_{s} i_{d s}+\omega_{s}\left(\left(L_{\sigma s}+L_{m}\right) i_{q s}+L_{m} i_{q r}\right) \\
& v_{q s}=-R_{s} i_{q s}-\omega_{s}\left(\left(L_{\sigma s}+L_{m}\right) i_{d s}+L_{m} i_{d r}\right) \\
& v_{d r}=0=-R_{r} i_{d r}+s \omega_{s}\left(\left(L_{\sigma r}+L_{m}\right) i_{q r}+L_{m} i_{q s}\right)+\frac{d \psi_{d r}}{d t} \\
& v_{q r}=0=-R_{r} i_{q r}-s \omega_{s}\left(\left(L_{\sigma r}+L_{m}\right) i_{d r}+L_{m} i_{d s}\right)+\frac{d \psi_{q r}}{d t}
\end{aligned}
$$

in which s equals the slip, $\mathrm{v}$ is voltage, $\mathrm{i}$ current, $\mathrm{R}$ resistance, $\mathrm{L}$ inductance, and $\psi$ flux linkage. All quantities are in per unit. The indexes $\mathrm{d}$ and $\mathrm{q}$ stand for direct and quadrature component, the indexes $\mathrm{s}$ and $\mathrm{r}$ for rotor and stator, $\mathrm{m}$ for mutual, and ó for leakage. The generator convention is used in this equation (i.e., currents are outputs).

The electrical torque is given by

$$
T_{e}=\psi_{q r} i_{q r}-\psi_{d r} i_{q r}
$$

The rotor flux components in (6) are state variables as can be seen from (5). The calculation of their initial values is discussed in [19]. The equation of motion is

$$
\frac{d \omega_{g}}{d t}=\frac{1}{2 H_{g}}\left(T_{g}-T_{e}\right) .
$$

The values of the various parameters are dependent on the generator rating and can be derived from tables and graphs [12]. The generator parameters used in this paper are given in Table 2. The compensating capacitors depicted in Fig. 1 are included in the grid model and are, therefore, not represented in the above equations that describe the constant speed generating system.

\section{Generating System With Doubly Fed Induction Generator}

1) Rotor Model: Again, a numerical approximation of the $c_{\mathrm{p}}(\lambda, \theta)$ curve has been developed using manufacturer documentation and multidimensional optimization. The values for the parameters in (2) and (3) can be found in Table 1. In the upper graph of Fig. 4, the resulting power curve is depicted, together with the power curves of two commercial variable speed wind turbines. The pitch angle deviation necessary to limit the power to the nominal value is depicted in the lower graph of Fig. 4.

Again, the low-pass filter depicted in Fig. 3 has been included in order to represent the smoothing of high-frequency windspeed components over the rotor surface. No tower shadow representation and shaft model have been included, because in variable speed wind turbines, the tower shadow and the torsional resonance of the shaft are hardly reflected in the output power, due to the decoupling of electrical and mechanical behavior by the power electronics [14], [15].

2) Model of Generator and Converter: The following equations describe the behavior of a doubly fed induction generator, again using the generator convention:

$$
\begin{aligned}
& v_{d s}=-R_{s} i_{d s}+\omega s\left(\left(L_{\sigma s}+L_{m}\right) i_{q s}+L_{m} i_{q r}\right) \\
& v_{q s}=-R_{s} i_{q s}-\omega_{s}\left(\left(L_{\sigma s}+L_{m}\right) i_{d s}+L_{m} i_{d r}\right) \\
& v_{d r}=-R_{r} i_{d r}+s \omega_{s}\left(\left(L_{\sigma r}+L_{m}\right) i_{q r}+L_{m} i_{q s}\right) \\
& v_{d r}=-R_{r} i_{q r}-s \omega_{s}\left(\left(L_{\sigma r}+L_{m}\right) i_{d r}+L_{m} i_{d s}\right) .
\end{aligned}
$$



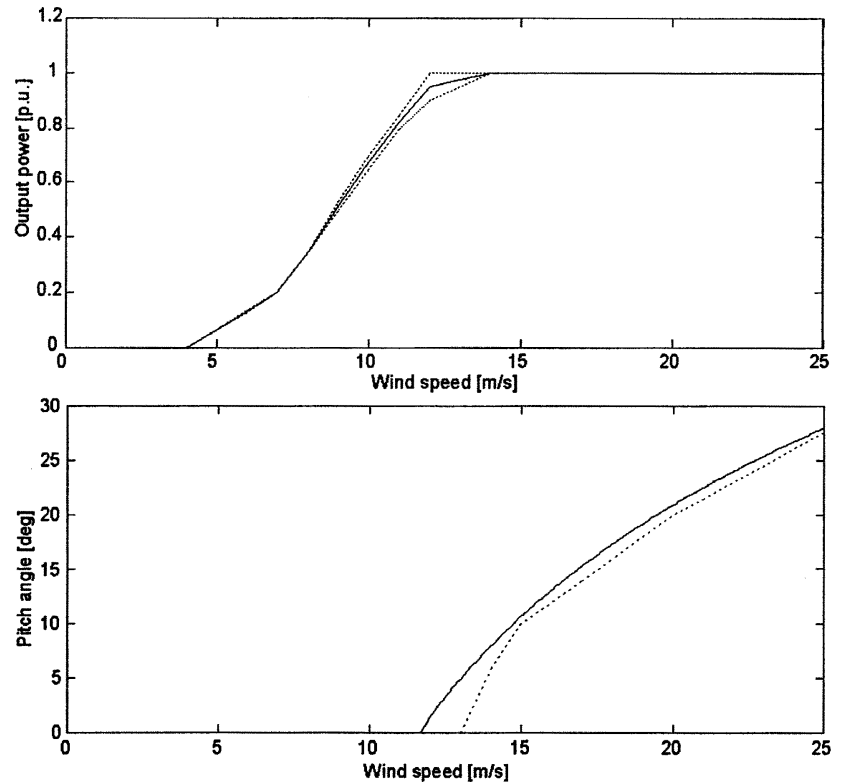

Fig. 4. Upper graph: comparison of numerical approximation of the power curve of a pitch controlled wind turbine (solid) with the power curves of two existing pitch controlled wind turbines (dotted). Lower graph: pitch angle deviation above nominal wind speed based on numerical approximation (solid) and manufacturer documentation (dotted).

TABLE II

SIMULATED INDUCTION GENERATOR PARAMETERS

\begin{tabular}{l|l}
\hline Generator characteristic & Value \\
\hline Number of poles & 4 \\
\hline Generator speed (constant speed) & 15 RPM \\
\hline Generator speed (doubly fed) & $1000-1900 \mathrm{RPM}$ \\
\hline Mutual inductance $\mathrm{L}_{\mathrm{m}}$ & 3.0 p.u. \\
\hline Stator leakage inductance $\mathrm{L}_{\sigma s}$ & 0.10 p.u. \\
\hline Rotor leakage inductance $\mathrm{L}_{\sigma r}$ & 0.08 p.u. \\
\hline Stator resistance $\mathrm{R}_{\mathrm{s}}$ & 0.01 p.u. \\
\hline Rotor resistance $\mathrm{R}_{\mathrm{r}}$ & 0.01 p.u. \\
\hline Compensating capacitor (constant speed) & 0.5 p.u. \\
\hline Moment of inertia & $0.5 \mathrm{~s}$ \\
\hline
\end{tabular}

In this equation, the $\mathrm{d} \psi / \mathrm{dt}$ terms in both the stator and rotor voltage equations are neglected. The stator transients are always neglected in fundamental frequency simulations [11]. The rotor transients are neglected because they are counteracted by the current control loops of the voltage source converter feeding the rotor winding. The current control loops have time constants that are well outside the bandwidth of interest in power system dynamics simulations. Therefore, the voltage source converter is modeled as a current source and the $\mathrm{d} \psi / \mathrm{dt}$ terms in the rotor voltage equations are neglected [17], [18].

The generated power is divided between the stator and the rotor

$$
\begin{aligned}
& P_{s}=v_{d s} i_{d s}+v_{d s} i_{q s} \\
& P_{r}=v_{d r} i_{d r}+v_{q r} i_{q r}
\end{aligned}
$$

in which $\mathrm{P}$ stands for active power. The torque equation and equation of motion are identical to (6) and (7) for the constant speed wind turbine. The rotor flux linkages occurring in (6) can be calculated with the following:

$$
\begin{aligned}
& \psi_{d r}=-L_{m} i_{d s}-\left(L_{m}+L_{\sigma}\right) i_{d r} \\
& \psi_{q r}=-L_{m} i_{q s}-\left(L_{m}+L_{\sigma}\right) i_{q r} .
\end{aligned}
$$

The generator parameters are given in Table 2.

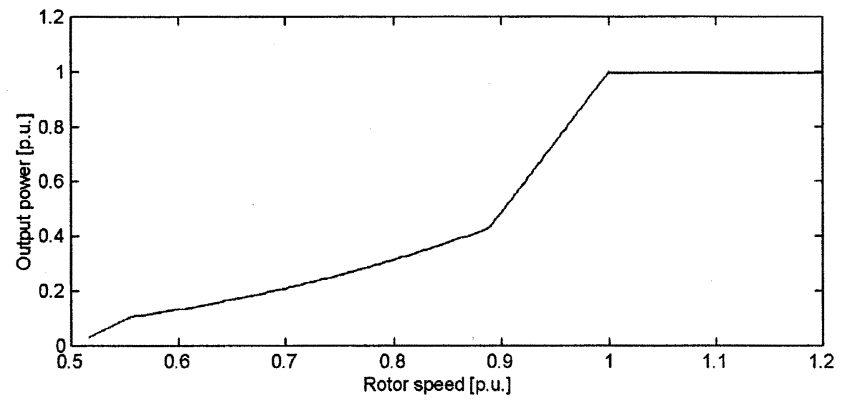

Fig. 5. Rotor speed versus power control characteristic.

The power electronic converter is represented by the following:

$$
\begin{aligned}
& P_{r}=P_{c}=v_{d c} i_{d c}+v_{q c} i_{q c} \\
& Q_{c}=0
\end{aligned}
$$

in which $\mathrm{Q}$ is reactive power in per unit and the index c stands for converter. From (11), it can be concluded that the power from the rotor circuit is injected into the grid and that the grid side of the converter is operated at unity power factor.

3) Rotor Speed Controller: In variable speed wind turbines, the rotor speed is controlled in order to obtain maximum energy yield. To this end, the tip speed ratio $\lambda$ is kept at the value that leads to the optimal $c_{p}$, while keeping the rotor speed within limits of the turbine [6], [15], [19]. From the actual value of the rotor speed, the wind speed that would correspond to the optimum value of $c_{p}$ is calculated. Then, the power that would be generated at this wind speed is calculated by substituting the wind speed in (1), together with the optimum value of $c_{p}$. This amount of power is then drawn from the generator by controlling the rotor current accordingly. The resulting power versus speed control characteristic is depicted in Fig. 5.

Without loss of generality, it can be assumed that the generator has its own dq reference frame in which the maximum of the stator flux coincides with the d-axis. To that end, the voltages and currents that are exchanged between the dynamics module and the load flow module of the software must be rotated with the angle of the bus to which the doubly fed induction generator is connected [20]. When thereafter (6), (8), and (10) are combined and the stator resistance is neglected, the following gives the relation between the quadrature component of the rotor current and the electro mechanical torque:

$$
T_{e}=\frac{-L_{m} v_{q s}}{\omega_{s}\left(L_{s}+L_{m}\right)} i_{q r}
$$

Equation (12) together with the actual value of the rotor speed can be used to control the generator power according to the control characteristic depicted in Fig. 5.

4) Pitch Angle Controller: When the wind speed is higher than the nominal value, the blades are pitched in order to limit the power extracted from the wind and the rotor speed. From Fig. 4, it can be concluded that the optimal pitch angle is approximately zero below the nominal wind speed and from there on increases steadily with increasing wind speed. This observation greatly facilitates pitch control.

It should be taken into account that the pitch angle cannot change immediately, but only at a finite rate, which may be quite 


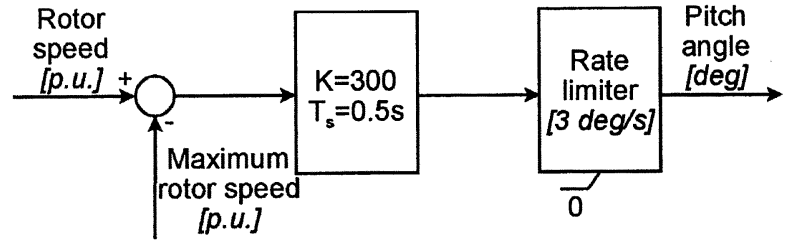

Fig. 6. Pitch angle controller.

low because of the size of the rotor blades of modern wind turbines and the desire to save money on the blade drives. Here, the maximum rate of pitch angle change is set to $3 \% \mathrm{~s}$ and the sampling time with which the rotor speed is sampled equals $0.5 \mathrm{~s}$. In Fig. 6, the pitch angle controller is depicted.

A proportional controller is used because

- a slight overspeeding of the rotor above its nominal value can be allowed [21];

- the system is never in steady state due to the varying wind speed, so that the advantage of an integral controller, which can achieve zero steady state error, is not applicable.

\section{E. Generating System With Direct Drive Synchronous Generator}

1) Rotor Model: The model of the rotor used in the generating system with direct drive synchronous generator is identical to that used in the doubly fed induction generator-based system. It was discussed above in Section IV-D-1.

2) Model of Generator and Converter: The following describe a wound rotor synchronous generator in the dq reference frame, taking into account the above assumptions:

$$
\begin{aligned}
\psi_{d s} & =-\left(L_{d m}+L_{\sigma s}\right) i_{d s}+L_{d m} i_{f d} \\
\psi_{q s} & =-\left(L_{q m}+L_{\sigma s}\right) i_{q s} \\
\psi_{f d} & =L_{f d} i_{f d} \\
v_{d s} & =-R_{s} i_{d s}-\omega_{g} \psi_{q s} \\
v_{q s} & =-R_{s} i_{q s}+\omega_{g} \psi_{d s} \\
v_{f d} & =R_{f d} i_{f d}+\frac{d_{q f d}}{d t} .
\end{aligned}
$$

The index fd indicates field quantities. Note that for the stator equations, the generator convention is used (i.e., positive currents are outputs). All quantities in (13) are in per unit values.

In case of a permanent magnet rotor, the third and sixth equation in (13), which are referring to field quantities, disappear and the upper equation becomes

$$
\psi_{d s}=-\left(L_{d s}+L_{\sigma s}\right) i_{d s}+\psi_{p m}
$$

in which $\psi_{\mathrm{pm}}$ equals the amount of flux of the permanent magnets mounted on the rotor that is coupled to the stator winding. The following gives the electromechanical torque:

$$
T_{e}=\psi_{d s} i_{q s}-\psi_{q s} i_{d s} .
$$

The equation of motion is given by (7).

As can be concluded from (13), the $\mathrm{d} \psi / \mathrm{dt}$ terms in the stator voltage equations are neglected. The associated time constants are small and taking them into account would result in the need to develop a detailed representation of the power electronic converter, which would include phenomena well outside the bandwidth of interest. Therefore, the power electronic
TABLE III

SiMULATED SYNCHRONOUS GENERATOR PARAMETERS

\begin{tabular}{l|l}
\hline Generator characteristic & Value \\
\hline Number of poles & 80 \\
\hline Generator speed & $9-19$ RPM \\
\hline Mutual inductance in d-axis $\mathrm{L}_{\mathrm{dm}}$ & 1.21 p.u. \\
\hline Mutual inductance in q-axis $\mathrm{L}_{\mathrm{qm}}$ & 0.606 p.u. \\
\hline Stator leakage inductance $\mathrm{L}_{\mathrm{s}}$ & 0.12 p.u. \\
\hline Stator resistance $\mathrm{R}_{\mathrm{s}}$ & 0.06 p.u. \\
\hline Field inductance $\mathrm{L}_{\mathrm{fd}}$ & 1.33 p.u. \\
\hline Field resistance $\mathrm{R}_{\mathrm{fd}}$ & 0.0086 p.u. \\
\hline Inertia constant & $1.0 \mathrm{~s}$ \\
\hline
\end{tabular}

converter is represented as a fundamental current source and the $\mathrm{d} \psi / \mathrm{dt}$ terms in the stator equations are neglected [18]. An instantaneous value model of this generating system can be found in the literature [8].

Active and reactive power of the direct-drive synchronous generator are given by

$$
\begin{aligned}
& P_{s}=v_{d s} i_{d s}+v_{q s} i_{q s} \\
& Q_{s}=v_{q s} i_{q s}-v_{d s} i_{q s} .
\end{aligned}
$$

It has to be noted that the generator is fully decoupled from the grid by the power electronic converter. Therefore, the power factor of the generator does not effect the reactive power factor at the grid connection, because the latter is determined by the grid side of the converter and not by the operating point of the generator. The second equation of (16) is, therefore, of limited interest when the grid interaction is studied, but is important when dimensioning the converter. The generator parameters are given in Table 3.

The following apply to the grid side of the power electronic converter:

$$
\begin{aligned}
P_{c} & =v_{d c} i_{d c}+v_{q c} i_{q c} \\
Q_{c} & =v_{q c} i_{d c}-v_{d c} i_{q c} .
\end{aligned}
$$

Since the grid side of the converter is equipped with current control loops, both active and reactive power output can be easily controlled using (17).

3) Rotor Speed Controller: The rotor speed versus control characteristic is identical to that used in the system with the doubly fed induction generator. However, different equations apply to the power drawn from the generator. The exact control approach depends on the generator and converter type. Four cases can be distinguished and are applied in practice, namely

- wound rotor generator with diode rectifier;

- permanent magnet generator with diode rectifier;

- wound rotor generator with voltage source converter;

- permanent magnet generator with voltage source converter.

When a diode rectifier is used, the generator power factor equals unity when commutation is neglected. In the upper equation of (13), the term $L_{d s} i_{f d}$ or in (14) the term $\psi_{\mathrm{pm}}$ is known. The excitation current $i_{f d}$ follows from the excitation voltage, which depends on the control strategy. Excitation control can (e.g., aim at generator loss minimization [22]). In a permanent magnet generator, the flux linkage of the permanent magnets $\psi_{\mathrm{pm}}$ is determined by the generator design. Further, the desired active power $\mathrm{P}$ is known, because it is derived from the actual value of the rotor speed $\omega_{m}$, according to Fig. 5. The following 
four equations with four unknowns result for a synchronous generator with a wound rotor:

$$
\begin{aligned}
v_{d s} & =-R_{s} i_{d s}+\omega_{g}\left(L_{q m}+L_{\sigma s}\right) i_{q s} \\
v_{q s} & =-R_{s} i_{q s}-\omega_{g}\left(\left(L_{d m}+L_{\sigma s}\right) i_{d s}-L_{d m} i_{f d}\right) \\
P_{s} & =v_{d s} i_{d s}+v_{q s} i_{q s} \\
Q_{s} & =v_{q s} i_{d s}-v_{d s} i_{q s}=0 .
\end{aligned}
$$

For a synchronous generator with permanent magnets, the second equation becomes

$$
v_{q s}=-R_{s} i_{q s}-\omega_{g}\left(\left(L_{d m}+L_{\sigma s}\right) i_{d s}-\psi_{p m}\right) .
$$

Equation (18) or (19) can be solved, after which the d and q components of stator voltage and current are known. By controlling the stator voltage of the generator accordingly, the desired operating point can be reached.

When instead of a diode rectifier, a back-to-back voltage source converter is used, not only the active power $\mathrm{P}$ but also the reactive power $\mathrm{Q}$ can be determined by the user. The last equation of (18) changes to

$$
Q_{s}=v_{q s} i_{d s}-v_{d s} i_{q s} .
$$

The other equations remain unchanged and again a system with four equations and four unknowns results.

When a back-to-back voltage source converter is used, not the stator voltage, but the stator currents are controlled. When the $\mathrm{d} \psi / \mathrm{dt}$ terms in the stator voltage equations are neglected, there is no difference between controlling the stator voltage and the stator current, as there is an algebraic relation between them. However, in more detailed investigations, in which e.g., the interaction between the generator and the converter is the topic of interest, substantial differences can be observed.

4) Pitch Angle Controller: The pitch angle controller used in the generating system with a direct drive synchronous generator is identical to that used in the generating system based on the doubly fed induction generator. The model was discussed above in Section IV-D-4.

\section{Simulation Results}

\section{A. Introduction}

In this section, the model's responses to a measured wind speed sequence will be investigated and compared to measurements. The measurements have been obtained from wind turbine manufacturers under a confidentiality agreement. Therefore, all values except wind speed and pitch angle are in per unit and their base values are not given.

The available measurements cannot readily be used for a quantitative validation of the model. This is caused by the fact that the wind speed is measured using a single anemometer, whereas the rotor has a large surface and by the fact that the measured wind speed is severely disturbed by the rotor wake, because the anemometer is located on the nacelle. The wind speed measured by the anemometer is thus not a good indication of the wind speed acting on the rotor as a whole.

It is, therefore, not allowed to use the wind-speed sequence measured by the anemometer as the model's input and to validate the model by comparing the measured and simulated response to that wind-speed sequence quantitatively. Instead, only
TABLE IV

SIMULATED WIND TURBINE PARAMETERS

\begin{tabular}{l|l}
\hline Turbine characteristic & Value \\
\hline Rotor speed (constant speed) & $17 \mathrm{RPM}$ \\
\hline Minimum rotor speed (variable speed) & $9 \mathrm{RPM}$ \\
\hline Nominal rotor speed (variable speed) & $18 \mathrm{RPM}$ \\
\hline Rotor diameter & $75 \mathrm{~m}$ \\
\hline Area covered by rotor & $4418 \mathrm{~m}^{2}$ \\
\hline Nominal power & $2 \mathrm{MW}$ \\
\hline Nominal wind speed (constant speed) & $15 \mathrm{~m} / \mathrm{s}$ \\
\hline Nominal wind speed (variable speed) & $14 \mathrm{~m} / \mathrm{s}$ \\
\hline Gear box ratio (constant speed) & $1: 89$ \\
\hline Gear box ratio (variable speed) & $1: 100$ \\
\hline Inertia constant & $2.5 \mathrm{~s}$ \\
\hline Shaft stiffness (constant speed) & 0.3 p.u./el. rad. \\
\hline
\end{tabular}
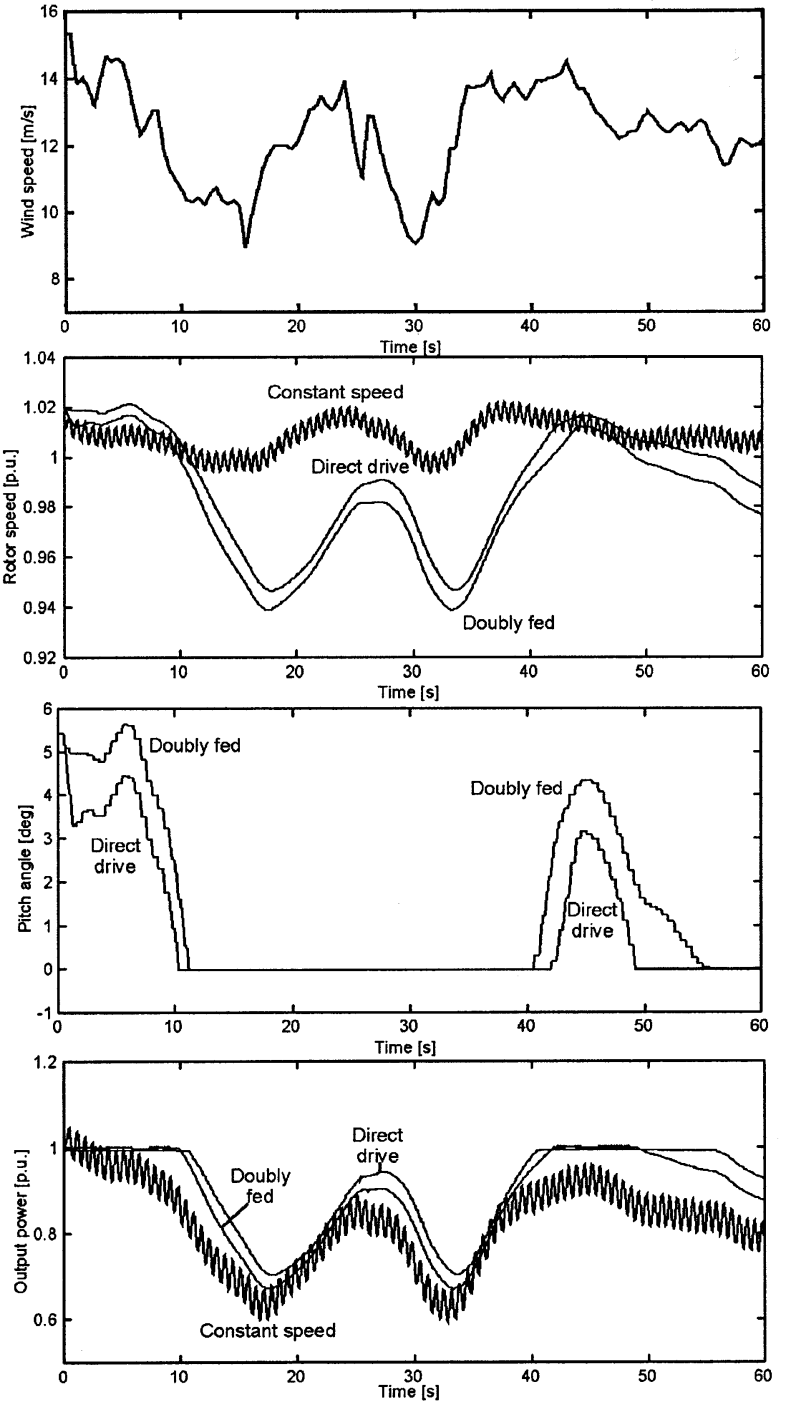

Fig. 7. Simulated responses to a measured wind speed. Starting from above: measured wind speed and simulated rotor speed, pitch angle, and output power. The meaning of the curves is indicated in the graphs.

a qualitative comparison is carried out and the same measured wind-speed sequence is used for all simulations.

\section{B. Simulation Results}

The characteristics of the simulated wind turbine are given in Table 4. In the upper graph of Fig. 7, a measured wind-speed se- 

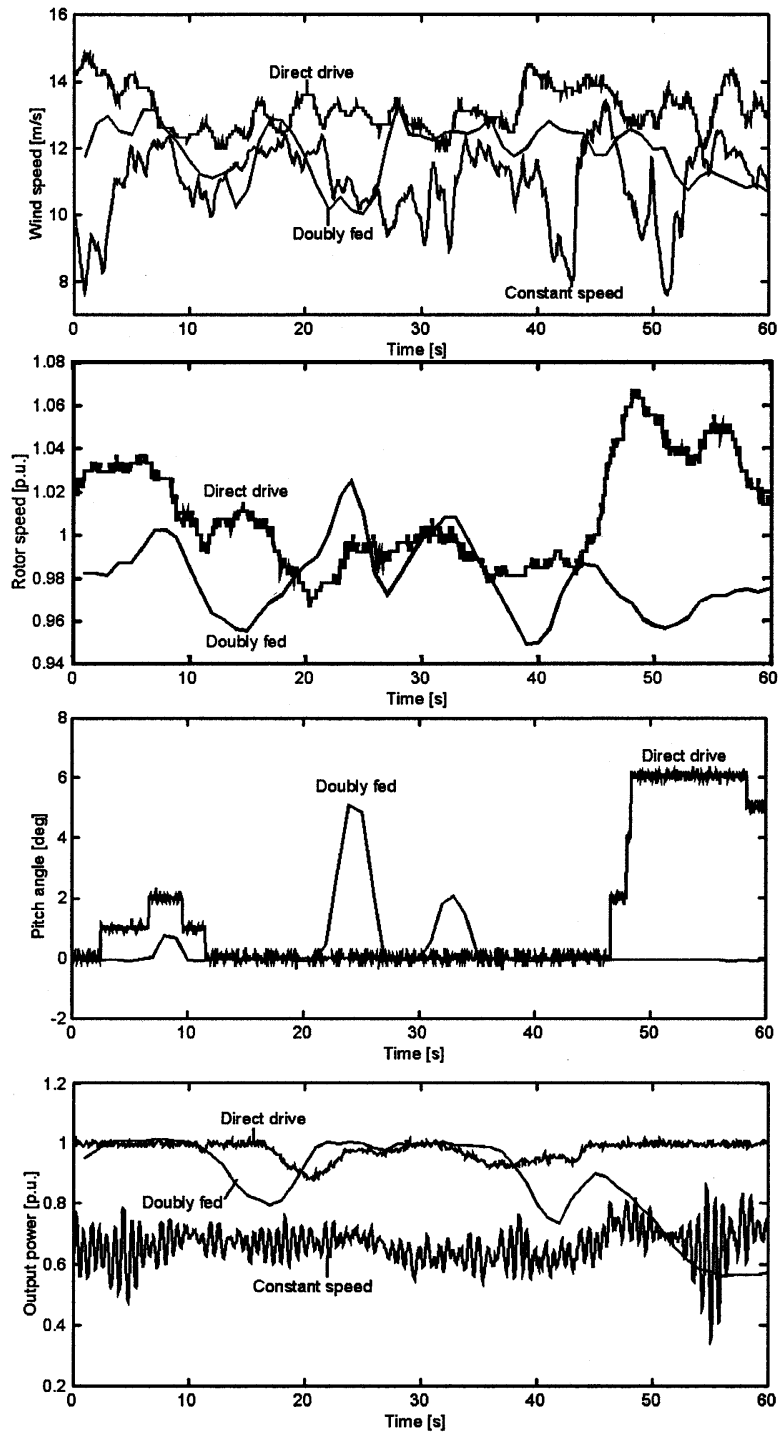

Fig. 8. Measured responses of each of the investigated wind turbine generating systems. Starting from above: measured wind speed, rotor speed, pitch angle, and output power. The meaning of the curves is indicated in the graphs.

quence is depicted. Then, the simulated rotor speed, pitch angle, if applicable, and the output power are depicted for each of the generating systems. The meaning of the curves is indicated in the graphs. By using a measured wind-speed sequence, the quite complex problem of modeling a wind-speed signal is avoided.

\section{Measurements}

In the upper graph of Fig. 8, three measured wind-speed sequences are depicted. Then, the measured rotor speed and pitch angle of both a variable speed wind turbine with doubly fed induction generator and with a direct drive synchronous generator are depicted. In the lower graph, the measured output power of all three turbines is depicted. The rotor speed of the constant speed wind turbine was not measured and is therefore not depicted. The meaning of each of the curves is again indicated in the graphs.

\section{Analysis of Results}

From the simulation results depicted in Fig. 7, the following can be concluded.

- Particularly short-term (seconds) output power fluctuations are more severe in case of a constant speed wind turbine than in case of both variable speed wind turbines. This is caused by the functioning of the rotor as an energy buffer in the variable speed wind generating systems.

- The response of the variable speed wind turbines is similar, which can be explained by noticing that their behavior is for the largest part determined by the controllers, which are identical.

These findings also apply to the measurements depicted in Fig. 8.

When the simulated and measured responses are compared, the following can be seen.

- The range of the measured and simulated rotor speed fluctuations of the variable speed turbines are similar (they fluctuate in a band of about 0.1 p.u. width).

- Measured and simulated pitch angle behavior are similar with respect to the rate of change $\left(\approx 3-5^{\circ} / \mathrm{s}\right)$ and the minimum $\left(\approx 0^{\circ}\right)$ and maximum value $\left(\approx 6^{\circ}\right)$.

- The range of the measured and simulated output power fluctuations of the constant speed wind turbine and of the wind turbine with doubly fed induction generator are similar (they fluctuate in a band of $\approx 0.3-0.4$ p.u. width).

- The rate of change of the measured and simulated output power fluctuations of the constant wind turbine shows differences. However, it can be seen that there is a rather poor correlation between the measured wind speed and output power in case of the constant speed wind turbine. The observed discrepancies between measurement and simulation are, therefore, at least partly caused by inaccuracies in the measurements, rather than by the model.

- The range of the measured $(\approx 0.2$ p.u.) and simulated $(\approx 0.4$ p.u. $)$ output power fluctuations of the wind turbine with direct drive synchronous generator is different. This is due to the fact that the direct drive wind turbine is only exposed to rather high wind speeds in the measurements, whereas in the simulation, also lower wind speeds occur.

Although, for reasons pointed out above, a quantitative validation of the models is not possible with the available measurements, this qualitative comparison gives at least some confidence in the accuracy and usability of the derived models and shows that the consequences of the assumptions and simplifications applied in modeling the rotor, the generator, and the controllers are limited.

\section{CONCLUSION}

In this paper, models of the three most important contemporary wind turbine generating systems were presented. The models are suitable for investigating the impact of large-scale connection of wind power on the dynamic behavior of electrical power systems. They match the simplifications applied in fundamental frequency simulations and all subsystems that determine the grid interaction are included in the models. 
When the response of the models to a measured wind-speed sequence is compared with measurements, an acceptable degree of correspondence can be observed. This gives confidence in the derived models and shows that the consequences of the applied simplifications are acceptable.

\section{ACKNOWLEDGMENT}

The wind-speed measurements were downloaded from "Database of Wind Characteristics" located at DTU, Denmark. The authors would like to thank Prof. Dr. Ir. G. A. M. van Kuik, the Wind Energy Institute at Delft UT, for making available his experience.

\section{REFERENCES}

[1] Feijóo, J. Cidrás, and C. Carillo, "A third order model for the doubly-fed induction machine," Elect. Power Syst. Res., vol. 56, no. 2, pp. 121-127, Nov. 2000.

[2] E. S. Abdin and W. Xu, "Control design and dynamic performance analysis of a wind turbine-induction generator unit," IEEE Trans. Energy Conversion, vol. 15, pp. 91-96, Mar. 2000.

[3] S. A. Papathanassiou and M. P. Papadopoulos, "Dynamic behavior of variable speed wind turbines under stochastic wind," IEEE Trans. Energy Conversion, vol. 14, pp. 1617-1623, Dec. 1999.

[4] - "Mechanical stresses in fixed-speed wind turbines due to network disturbances," IEEE Trans. Energy Conversion, vol. 16, pp. 361-367, Dec. 2001.

[5] S. Bhowmik, R. Spée, and J. H. R. Enslin, "Performance optimization for doubly fed wind power generation systems," IEEE Trans. Ind. Applicat., vol. 35, pp. 949-958, July/Aug. 1999.

[6] E. A. Bossanyi, "The design of closed loop controllers for wind turbines," Wind Energy, vol. 3, no. 3, pp. 149-163, July/Sept. 2000.

[7] V. Akhmatov, H. Knudsen, and A. H. Nielsen, "Advanced simulation of windmills in the electric power supply," Int. J. Elect. Power Energy Syst., vol. 22, no. 6, pp. 421-434, Aug. 2000.

[8] Z. Chen and E. Spooner, "Grid power quality with variable speed wind turbines," IEEE Trans. Energy Conversion, vol. 16, pp. 148-154, June 2001.

[9] A. S. Neris, N. A. Vovos, and G. B. Giannakopoulos, "A variable speed wind energy conversion scheme for connection to weak AC systems," IEEE Trans. Energy Conversion, vol. 14, pp. 122-127, Mar. 1999.

[10] J. Rösner, H. P. Beck, and C. Sourkounis, "Wind energy converter with asynchronous machines and three-phase $\mathrm{AC}$ controller in generator mode," Eur. Trans. Elect. Power, vol. 10, no. 4, pp. 253-258, July/Aug. 2000.

[11] P. Kundur, Power System Stability And Control. New York: McGrawHill, 1994.

[12] S. Heier, Grid Integration of Wind Energy Conversion Systems. Chicester, U.K.: Wiley, 1998.

[13] M. R. Patel, Wind and Solar Power Systems. Boca Raton, FL: CRC Press, 2000

[14] T. Petru and T. Thiringer, "Active flicker reduction from a sea-based 2.5MW wind park connected to a weak grid," in Proc. Nordic Workshop Power Ind. Electron., Aalborg, Denmark, June 13-16, 2000.

[15] T. Krüger and B. Andresen, "Vesta OptiSpeed-advanced control strategy for variable speed wind turbines," in Proc. Eur. Wind Energy Conf., Copenhagen, Denmark, July 2-6, 2001, pp. 983-986.

[16] Modeling New Forms Of Generation And Storage, N. Hatziargyriou, Ed., CIGRE TF 38.01.10, Paris, France, Nov. 2000.
[17] M. Fujimitsu, T. Komatsu, K. Koyanagi, K. Hu, and R. Yokoyama, "Modeling of doubly-fed adjustable-speed machine for analytical studies on long-term dynamics of power system," in Proc. IEEE PowerCon, vol. 1, Perth, Australia, Dec. 4-7, 2000, pp. 25-30.

[18] J. G. Slootweg, S. W. H. de Haan, H. Polinder, and W. L. Kling, "Modeling wind turbines in power system dynamics simulations," in Proc. IEEE Power Eng. Soc. Summer Meeting, Vancouver, BC, Canada, July $15-19,2001$.

[19] J. G. Slootweg, H. Polinder, and W. L. Kling, "Initialization of wind turbine models in power system dynamics simulations," in Proc. IEEE Porto Power Tech, Porto, Portugal, Sept. 10-13, 2001.

[20] G. C. Paap, "Symmetrical components in the time domain and their application to power network calculations," IEEE Trans. Power Syst., vol. 15, pp. 522-528, May 2000.

[21] E. Muljadi and C. P. Butterfield, "Pitch-controlled variable-speed wind turbine generation," IEEE Trans. Ind. Applicat., vol. 37, pp. 240-246, Jan./Feb. 2001

[22] H. Polinder and J. G. Slootweg, "Design optimization of a synchronous generator for a direct drive wind turbine," in Proc. Eur. Wind Energy Conf., Copenhagen, Denmark, July 2-6, 2001, pp. 967-970.

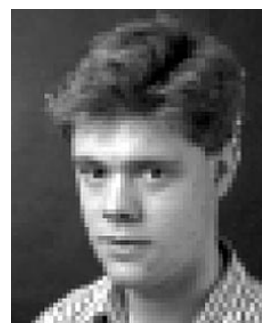

J. G. Slootweg (M'01) received the M.Sc. degree in electrical engineering from Delft University of Technology, Delft, The Netherlands, in 1998. He is currently pursuing the Ph.D. degree on large-scale integration of dispersed generation into existing electric grids at the Electrical Power Systems Laboratory, Delft University of Technology.

$\mathrm{He}$ stayed in Berlin for six months, hearing lectures at TU Berlin and conducting research at the Dynamowerk of Siemens AG, Berlin, Germany.

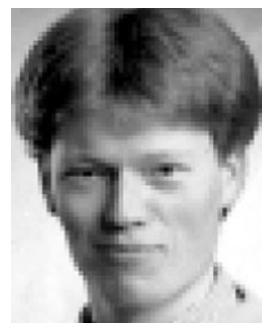

H. Polinder (M'97) received the M.Sc. and Ph.D. degrees in electrical engineering from Delft University of Technology, Delft, The Netherlands, in 1992 and 1998, respectively.

Currently, he is an Assistant Professor at the Electrical Power Processing Laboratory, Delft University of Technology, where he gives courses on electrical machines and drives. His main research interest is the field of generator systems in renewable energy, such as wind energy and wave energy.

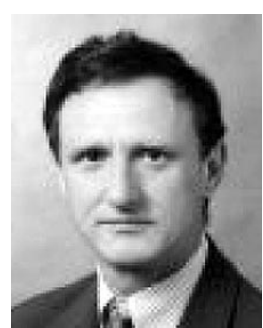

W. L. Kling (M'95) received the M.Sc. degree in electrical engineering from the Technical University of Eindhoven, The Netherlands, in 1978.

Currently, he is a part-time Professor at the Electric Power Systems Laboratory, Delft University of Technology, Delft, The Netherlands. His experience is in the area of planning and operation of power systems.

Mr. Kling is involved in scientific organizations such as Cigré and IEEE. He is the Dutch Representative in the Cigré Study Committee C1 Planning and Development of Power Systems. 